\title{
Avaliação do sistema de pulverização com funcionamento intermitente, acoplado ao pivô central, Notliada ${ }^{1}$
}

\author{
Robson A. Armindo ${ }^{2}$, Tarlei A. Botrel ${ }^{3}$, Durval Dourado Neto $^{3}$ \& Gerson B. Mourão
}

\begin{abstract}
RESUMO
Teve-se como objetivo, no presente trabalho, avaliar o desvio existente entre as vazões estimadas e observadas dos emissores presentes no sistema de pulverização acoplado ao pivô central, Notliada. Os testes foram realizados em um protótipo do sistema, montado em uma área anexa ao Laboratório de Hidráulica do Departamento de Engenharia Rural (LER) pertencente à Escola Superior de Agricultura "Luiz de Queiroz" - ESALQ/USP. Os resultados obtidos mostraram que os modelos gerados dos desvios relativos existentes entre as vazões estimadas e observadas em função da freqüência de operação da válvula solenóide apresentaram excelentes índices de precisão e exatidão. Encontrou-se um tempo mínimo de 1,0 s em que a válvula solenóide deve permanecer ligada para os emissores de diâmetro 1,212 (preto), 1,016 (vermelho) e 1,020 mm (laranja); para o emissor de diâmetro 0,621 mm (azul), esse tempo mínimo encontrado foi de 1,4 s. A mesma válvula pode permanecer desligada durante qualquer intervalo de tempo entre 3 e $9 \mathrm{~s}$ para todos os emissores testados. Os emissores preto e laranja indicaram índices inaceitáveis de uniformidade de aplicação para tempos de acionamento menores que 0,7 s. Os emissores azul e vermelho indicaram excelentes índices para qualquer intervalo de tempo de acionamento. Enfim, todos os emissores indicaram excelentes índices de uniformidade para todos os intervalos de tempo de desligamento da válvula solenóide testados.
\end{abstract}

Palavras-chave: quimigação, válvula solenóide, automação

\section{Evaluation of a pulverization system, with emitters working in intermittent mode, on a Notliada central pivot}

\begin{abstract}
The aim of this study was to evaluate the difference between estimated and observed emitter flow rates presented by the Notliada pulverization system. The research was undertaken in the Hydraulic Laboratory/Rural Engineering Department at "Luiz de Queiroz" College of Agriculture, University of São Paulo, Brazil. The proposed models showed excellent precision and accuracy indexes. It was determine that emitters of diameter 1.212 (black), 1.016 (red) and $1.020 \mathrm{~mm}$ (orange); the solenoid valve must stay turned on for a minimum time of $1.0 \mathrm{~s}$. For the blue emitter of $0.621 \mathrm{~mm}$ diameter, this time was $1.4 \mathrm{~s}$. The solenoid valve can be kept turned off for any time between 3 and $9 \mathrm{~s}$. The black and orange emitters had unacceptable uniformity application indexes for turn on times less than $0.7 \mathrm{~s}$. The blue and red emitters had excellent indexes for any tested turn on times. All emitters had excellent uniformity indexes for all tested turn off times used on the solenoid valve.
\end{abstract}

Key-words: chemigation, solenoid valve, automation

Parte da Dissertação de Mestrado do primeiro autor apresentada ao curso de Pós-Graduação em Irrigação e Drenagem da Universidade de São Paulo 2 ESALQ/USP. Av Pádua Dias 11, CP 9, CEP 13418-900, Piracicaba, SP. Fone: (19) 3447-8514. E-mail: rarmindo@esalq.usp.br

DPV/ESALQ. E-mail: tabotrel@esalq.usp.br; dourado@esalq.usp.br; gbmourao@esalq.usp.br 


\section{INTRODUÇÃO}

Na última década, com a degradação ambiental do planeta, foi assustador, também, o crescimento da preocupação com o futuro. A aplicação, mesmo com baixa uniformidade, de lâminas de água e fertilizantes reduz a eficiência do manejo na agricultura irrigada desprotegendo as fontes de água, deixando-as à mercê da própria sorte. Uma alternativa que se vislumbra é a utilização de mecanismos de aplicação de taxa variada o que, auxiliará sem dúvida, no aumento da uniformidade de aplicação e na redução da aplicação superestimada de fertilizantes. Além disso, a aplicação eficiente de agroquímicos é uma alternativa que ajuda a manter um sistema de produção economicamente estável.

Utilizam-se, atualmente, alguns sistemas para a pulverização no campo. Os pulverizadores costais, tratores, aviões, pivôs centrais e sistemas acoplados aos pivôs centrais podem ser utilizados para a aplicação de herbicidas, fungicidas, inseticidas e fertilizantes. Entretanto, as viabilidades técnica e econômica para esses sistemas podem ser discutidas.

Para se cultivar grandes áreas requer-se, na maioria das vezes, a utilização de defensivos agrícolas dentre outras tecnologias modernas. As aplicações de tais produtos são feitas mediante pulverizações ou via água de irrigação, técnica conhecida por quimigação. Elevada lâmina de água e de produtos químicos é aplicada na quimigação pelo pivô central. Alves (2000) comenta que apenas um pequeno gradiente ativo fica retido nas folhas da planta, o que reduz sensivelmente a eficiência, como exemplo em torno de $2 \%$ para o milho, desse sistema de aplicação. A razão das diferenças mostradas anteriormente se reflete na variação das velocidades dos equipamentos de pulverização que podem variar de 10 a $300 \mathrm{~km} \mathrm{~h}^{-1}$, no caso de pulverizadores terrestres ou aéreos; contudo, para os pivôs centrais as velocidades podem variar de 0,12 a $0,34 \mathrm{~km} \mathrm{~h}^{-1}$.

De acordo com Vilela (2002) sistemas acoplados a pivôs centrais são constituídos, em sua maioria, de equipamentos independentes dos sistemas de distribuição de água dos pivôs centrais. Esses sistemas por sua vez, têm por objetivo, comparados aos pivôs centrais, atingir menores lâminas de aplicação e menores diâmetros de gotas, além de maior eficiência de aplicação e, como exemplo, pode-se citar o sistema intermitente de pulverização acoplado a pivô central Notliada. De acordo com Vilela et al. (2004), utilizando-se o sistema Notliada, pode-se efetuar a quimigação com uma calda de aplicação de 286,7 L ha-1, com um diâmetro médio volumétrico (DMV) de 126,30 $\mu \mathrm{m}$ e uma uniformidade de aplicação satisfatória, classificada de acordo com Cupery (1987). Farahani et al. (2006) modificaram o sistema de pulverização Accu-Pulse obtendo-se aplicações com 50 a 75\% a mais de cobertura de produto sobre a folha e coeficientes de variação de 13 a 34\% para aplicações menores que $19 \mathrm{~mL}$ por pulso.

Bralts et al. (1982) recomendam o uso da uniformidade estatística, “Us”, na avaliação das linhas laterais de um sistema de irrigação localizada. A justificativa reside no fato de que, nessa abordagem estatística, todos os fatores que influenciam a uniformidade podem ser incluídos na sua es- timativa final; esses fatores são: a perda de carga, o desnível topográfico, a variação na fabricação dos emissores e o entupimento. Ainda segundo Vilela (2002), testes com o sistema Notliada apresentaram valores de calda estimados maiores que valores de caldas observados. Essas variações podem ser explicadas, possivelmente, por diversas causas, tais como tempo de resposta hidráulico diferenciado em cada pulso, erro metodológico de coleta e amostragem e possíveis evaporações decorridas depois da exposição dos coletores à pulverização, dentre outras.

Baio (2001) cita que um dos fatores mais importantes que definem a eficiência de um equipamento para a aplicação localizada de defensivos, em realizar a pulverização da dosagem correta sobre o local desejado, é seu tempo de resposta.

Para se aplicar baixas vazões em sistemas acoplados a pivôs centrais seria necessário reduzir-se a pressão sobre o conjunto de emissão ou mesmo o diâmetro dos emissores. A primeira opção é inviável tecnicamente, uma vez que o alcance do emissor, a operação da válvula antigotas e outras características do conjunto dependem da pressurização. Reduzir o diâmetro do emissor pode gerar problemas na aplicação como o entupimento. Dessa forma, a aplicação intermitente se torna uma alternativa de redução de vazão tecnicamente viável. Na aplicação pulsante a vazão do conjunto de emissão passa a depender da freqüência de operação do sistema, além da pressão exercida sobre o mesmo. A freqüência é função do tempo em que o sistema permanece ligado (tl) e do tempo em que o mesmo permanece desligado (td). Pequenas vazões são adquiridas diminuindo-se "tl” e se aumentando "td"; entretanto, pequenos valores de "tl" podem gerar erros causados pelo tempo de resposta e outros fatores hidráulicos do sistema. Altos valores de "td" ocasionam falhas no molhamento da cultura gerando ausência de uniformidade de aplicação. Acredita-se, assim, que exista uma faixa ótima de freqüência de operação que garanta uma vazão reduzida dos emissores confiável e uniforme. Assim sendo se objetivou neste trabalho modelar o desvio relativo existente entre as vazões estimada e observada para estabelecer freqüências ideais de operação de um sistema de pulverização intermitente.

\section{MATERIAL E MÉTODOS}

\section{Localização e etapas do experimento}

Desenvolveu-se este trabalho no Departamento de Engenharia Rural da Escola Superior de Agricultura "Luiz de Queiroz” (ESALQ), da Universidade de São Paulo (USP), no município de Piracicaba, SP. O protótipo do sistema foi instalado em uma área anexa ao Laboratório de Hidráulica do Departamento de Engenharia Rural, no campus dessa Universidade, onde se realizaram as devidas análises. Os equipamentos individuais que integraram o protótipo foram testados previamente no laboratório.

\section{Avaliação do protótipo da barra de pulverização}

No projeto da barra de pulverização foram observados todos os detalhes e metodologias descritas por Vilela (2002). 
Dessa forma, o protótipo do sistema Notliada foi produzido em semelhança com o sistema montado anteriormente sobre o pivô central. Todas as avaliações foram feitas com água pura, como em geral são realizadas em ensaios de pulverização.

\section{Sistema hidráulico da barra de pulverização}

O sistema hidráulico foi composto de: emissores, dispositivos antidrenantes, conectores, barra de pulverização, válvula solenóide, regulador de pressão, tubulações de alimentação, conjunto motobomba, reservatório, registros, filtragem, conjunto de fixação, dentre outros.

Utilizaram-se conjuntos de emissão Fogger 7800 de diâmetros 0,$621 ; 1,016 ; 1,020 ; 1,212$ mm codificados, de acordo com o fabricante, respectivamente pelas cores: azul, vermelho, laranja e preto. codificados pelas cores: azul, vermelho, laranja e preto que representam os diâmetros e as vazões nominais desses emissores em diversos catálogos fornecidos pelo fabricante. Submeteram-se esses conjuntos de emissão a um processo de limpeza e desentupimento antes de serem instalados na barra de pulverização. Primeiramente se desmontaram os emissores, conectores e válvulas anti-gotas, colocando-os em contato com água a uma concentração de 10 ppm de cloro $(\mathrm{Cl})$ pelo tempo de $48 \mathrm{~h}$. Decorrido esse período, utilizou-se um compressor de ar para efetuar a limpeza dos mesmos. A pressão de serviço utilizada foi de $245 \mathrm{kPa}$ para os quatro tipos de emissores utilizados sendo preparados e instalados em uma tubulação de PVC soldável com diâmetro de 0,025 m; já a barra de pulverização foi montada a uma altura de $0,50 \mathrm{~m}$ do solo. Adaptou-se uma tomada de pressão no início da tubulação e outra em seu final a fim de se determinar a perda de pressão entre o início e o final da barra durante o funcionamento do sistema. Apresenta-se, na Figura 1, a imagem do protótipo montado para avaliação.

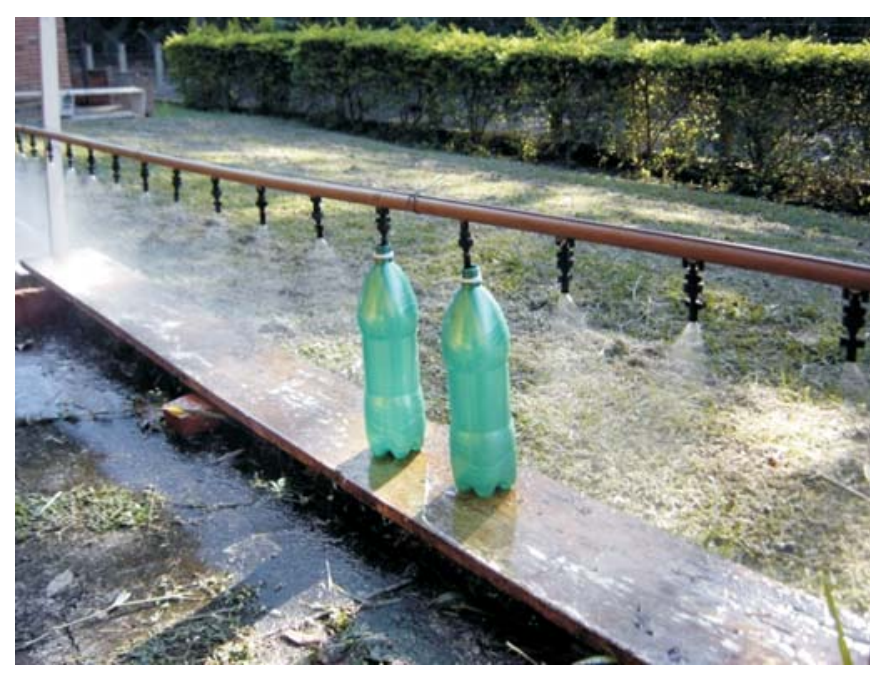

Figura 1. Barra de pulverização construída para as avaliações

Na entrada da barra de pulverização se instalou uma válvula solenóide, objetivando-se controlar o fluxo hidráulico. Determinaram-se as curvas de vazão em função da pressão para os conjuntos de emissão variando-se a pressão do sistema de 205 a $435 \mathrm{kPa}$.
Descrição geral do funcionamento do sistema hidráulico

A água utilizada nos testes foi pressurizada pelo conjunto motobomba e conduzida, por meio das tubulações de alimentação, até a entrada do regulador de pressão; desse ponto em diante, o fluido passou a ser transportado por uma tubulação flexível até a válvula solenóide. Posicionou-se a válvula solenóide no início da barra de pulverização apresentando a função de controlar a vazão para o interior da barra por meio de comandos enviados por um circuito eletroeletrônico.

A barra de pulverização esteve totalmente preenchida, devido à ação estanque das válvulas anti-gotas, possibilitando a operação dos emissores quase instantaneamente à abertura da válvula solenóide.

\section{Circuito eletroeletrônico}

O efeito de intermitência do sistema Notliada dependeu da ação do circuito eletroeletrônico e da válvula solenóide. Esse circuito foi comandado por um algoritmo inserido em um microcontrolador do tipo Basic Step, fabricado pela empresa Tato Equipamentos Eletrônicos Ltda. Apresenta-se, na Figura 2, o esquema do circuito eletroeletrônico utilizado.

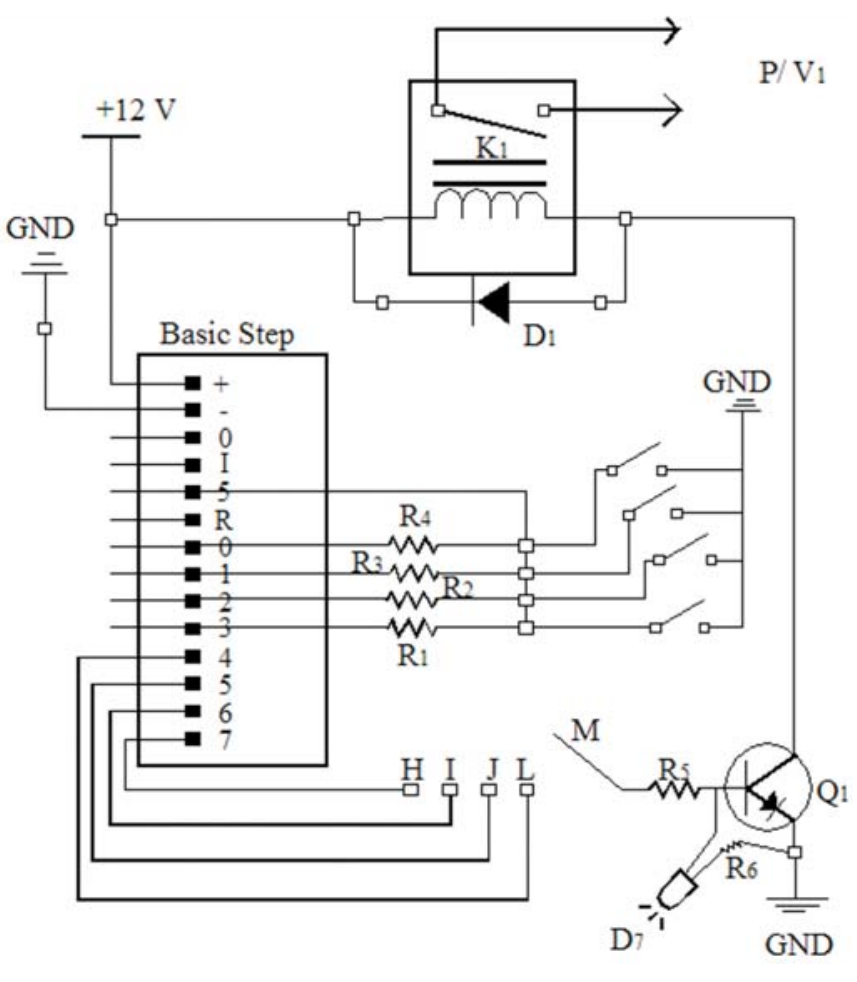

Figura 2. Esquema do circuito de acionamento da válvula solenóide utilizado

O programa para acionamento da válvula solenóide foi desenvolvido em linguagem denominada tbasic; depois de sua conclusão, o programa foi enviado para o microcontrolador, por meio da porta serial do computador. Para a válvula solenóide utilizou-se uma bateria de 12 Vcc capaz de fornecer a carga demandada por essa válvula.

\section{Efeito intermitente do protótipo do sistema Notliada}

Obteve-se a realização da pulverização de forma variada no sistema Notliada mediante a intermitência da válvula 
solenóide na entrada da barra de pulverização; assim, o sistema foi pressurizado no intervalo (tl) aplicando-se a calda programada. Esse tempo corresponde ao intervalo em que a válvula inicia o primeiro pulso até o início do segundo. O tempo desligado (td) também é responsável pelo efeito de redução da calda. O período de um ciclo da válvula solenóide corresponde ao intervalo de tempo suficiente para que ela realize dois pulsos. No início do ciclo a válvula recebe o primeiro pulso, sendo pressurizada e, logo em seguida, recebe o segundo, sendo daí desenergizada. Sabendo-se que o período (T) é o inverso da freqüência, apresenta-se a Eq. 1 para estimar a vazão aplicada por um único emissor no protótipo projetado.

$$
\mathrm{q}_{\text {est }}=\mathrm{k} \mathrm{H}^{\mathrm{x}} \mathrm{tl} \mathrm{f}
$$

em que:

$$
\begin{aligned}
\text { qest }- \text { vazão estimada de um emissor com taxa varia- } & \text { da, } \mathrm{m}^{3} \mathrm{~s}^{-1} \\
\mathrm{k} \text { - } & \text { constante, } \mathrm{m}^{5 / 2} \mathrm{~s}^{-1} \\
\mathrm{H} \text { - } & \text { pressão atuante no emissor, } \mathrm{kPa} \\
\mathrm{x} \text { - } & \text { parâmetro de ajuste da função } \\
\mathrm{tl} \text { - } & \text { tempo em que a válvula solenóide permanece } \\
& \text { ligada, } \mathrm{s} \\
\mathrm{f} \text { - } & \text { freqüência de operação da válvula, ciclo } \mathrm{s}^{-1}
\end{aligned}
$$

\section{Método de trabalho}

A avaliação de desempenho do sistema Notliada foi realizada avaliando-se o desvio existente entre a vazão observada e a vazão estimada do sistema. Realizou-se, depois da montagem do sistema, a determinação da curva pressão versus vazão dos quatro conjuntos de emissão. As pressões utilizadas na determinação foram de 205, 255, 275, 295, 315, 335, 355, 375, 395, 415 e $435 \mathrm{kPa}$. As vazões foram determinadas pelo método gravimétrico utilizando-se garrafas pet para a coleta do volume; logo em seguida, os recipientes foram levados a uma balança para a determinação do peso da água coletada. Dividiu-se esse valor pelo tempo de coleta, uma vez que se considerou a densidade da água igual à unidade. Para cada ponto de pressão foram realizadas três coletas por conjunto de emissão, determinando-se a vazão média de cada conjunto. De posse dos valores médios de vazão calculados e dos pontos de pressão utilizados, realizaram-se quatro regressões para determinação do modelo que melhor se ajustava aos dados observados de pressão em função da vazão.

Realizaram-se, depois desses procedimentos, dois experimentos para a determinação do desvio existente entre as vazões observadas e estimadas. No primeiro se manteve o tempo de desligamento da válvula solenóide constante, variando-se os tempos de ligamento; já no segundo se variou, além do tempo de ligamento da válvula solenóide, seu tempo de desligamento. A pressão de serviço do ensaio foi de $245 \mathrm{kPa}$, pressão de saída do regulador utilizado.

\section{RESULTADOS E DISCUSSÃO}

\section{Determinação da curva vazão versus pressão}

Os valores médios de vazão para os diferentes tipos de emissores e valores de pressão são apresentados na Tabela 1.
Tabela 1. Vazões médias coletadas nos diferentes emissores para diferentes pressões

\begin{tabular}{ccccc}
\hline $\begin{array}{c}\text { Pressão } \\
(\mathbf{k P a})\end{array}$ & \multicolumn{4}{c}{ Vazão média dos emissores $\left(\mathbf{L} \mathbf{h}^{-1}\right)$} \\
\cline { 2 - 5 } ) & Preto & Laranja & Azul & Vermelho \\
205 & 16,39 & 8,84 & 4,34 & 12,87 \\
255 & 18,28 & 9,64 & 4,79 & 13,90 \\
275 & 19,00 & 10,19 & 5,15 & 14,73 \\
295 & 19,61 & 10,64 & 5,31 & 15,13 \\
315 & 20,53 & 11,00 & 5,44 & 15,92 \\
335 & 21,13 & 11,43 & 5,69 & 16,53 \\
355 & 21,89 & 11,81 & 5,96 & 17,04 \\
375 & 22,65 & 12,14 & 6,11 & 17,53 \\
395 & 23,86 & 12,67 & 6,32 & 17,88 \\
415 & 24,38 & 12,89 & 6,54 & 18,61 \\
435 & 24,69 & 13,06 & 6,59 & 18,98 \\
\hline
\end{tabular}

De acordo com as Eqs. 2 e 3, foram calculados, segundo Bralts et al. (1987) o coeficiente de variação (CVq) e a uniformidade estatística (Us) dos ensaios realizados.

$$
\begin{gathered}
\mathrm{CVq}=\frac{\mathrm{S}}{\mathrm{q}_{\mathrm{m}}} \\
\mathrm{Us}=100(1-\mathrm{Cvq})
\end{gathered}
$$

em que:

CVq - coeficiente de variação das vazões observadas, adimensional

$\mathrm{S}$ - desvio padrão das vazões observadas, $\mathrm{L} \mathrm{h}^{-1}$

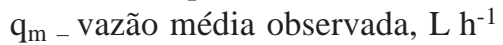

Us - uniformidade estatística, \%

Apresentam-se, na Tabela 2, os valores de uniformidade estatística calculados.

Tabela 2. Uniformidade estatística das vazões dos emissores utilizados

\begin{tabular}{ccccc}
\hline $\begin{array}{c}\text { Pressão } \\
\text { (kPa) }\end{array}$ & \multicolumn{4}{c}{ Us (\%) } \\
\cline { 2 - 5 } 205 & Preto & Laranja & Azul & Vermelho \\
245 & 95,44 & 98,59 & 95,40 & 95,22 \\
255 & 93,42 & 97,19 & 97,39 & 95,19 \\
275 & 93,69 & 98,36 & 96,73 & 95,73 \\
295 & 95,80 & 97,81 & 96,17 & 95,23 \\
315 & 96,11 & 96,02 & 97,35 & 95,88 \\
335 & 95,62 & 96,04 & 95,27 & 96,05 \\
355 & 95,77 & 95,54 & 96,01 & 96,12 \\
375 & 96,23 & 95,32 & 94,94 & 95,19 \\
395 & 96,04 & 94,96 & 93,39 & 95,86 \\
415 & 96,75 & 95,09 & 92,12 & 96,15 \\
435 & 97,03 & 94,14 & 93,65 & 95,03 \\
\hline
\end{tabular}

Conforme os resultados da Tabela 2, as uniformidades estatísticas calculadas apresentaram valores excelentes, segundo Bralts et al. (1982), o que garante boa confiabilidade nas funções geradas nesse ensaio. Na Figura 3 se encontram as curvas vazão versus pressão para os emissores pretos, laranja, azul e vermelho e, na Tabela 3, seus parâmetros de ajuste. 


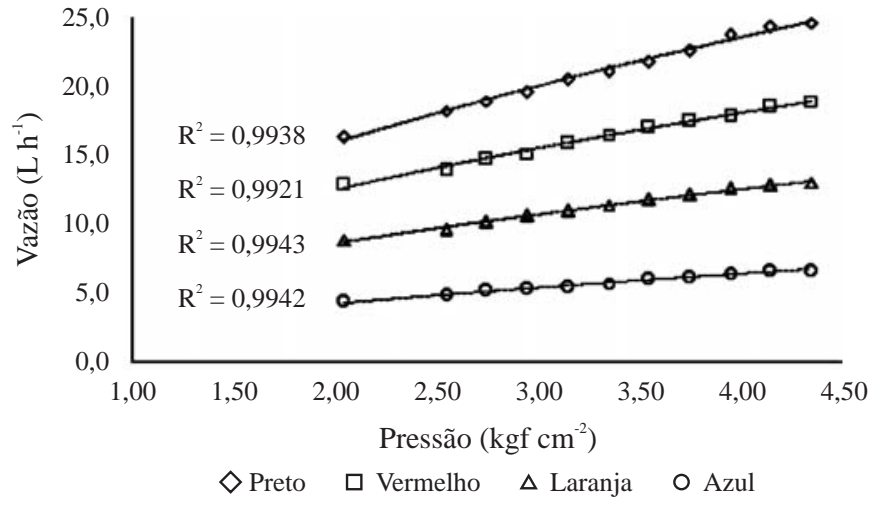

Figura 3. Curvas vazão versus pressão para os conjuntos de emissão utilizados

Tabela 3. Parâmetros de ajuste das equações geradas para os conjuntos de emissão utilizados.

\begin{tabular}{ccc}
\hline \multirow{2}{*}{ Emissores } & \multicolumn{2}{c}{ Parâmetros } \\
\cline { 2 - 3 } Preto & 10,6608 & $\mathbf{X}$ \\
Vermelho & 8,3943 & 0,5741 \\
Laranja & 5,8463 & 0,5510 \\
Azul & 2,8221 & 0,5534 \\
\hline
\end{tabular}

Comparação entre os valores de vazão estimados e observados com a válvula solenóide operando com tempo de desligamento constante

Com base nos resultados obtidos do primeiro experimento, observou-se que cada emissor apresentou diferentes respostas aos intervalos de acionamento da válvula solenóide. Calculou-se, assim, o desvio relativo (Dr) entre as vazões estimadas e as vazões observadas, de acordo com a Eq. 4.

$$
\operatorname{Dr}=\frac{\left|\mathrm{q}_{\text {est }}-\mathrm{q}_{\text {obs }}\right|}{\mathrm{q}_{\text {est }}} \times 100
$$

em que: $\mathrm{Dr}$ - desvio relativo, \%

$\mathrm{O}$ teste $\mathrm{F}$ dos desvios relativos pode ser constatado na Tabela 4, verificando-se diferença significativa entre as vazões observadas e estimadas em função do tempo em que a válvula solenóide permaneceu ligada, do tipo de conjunto de emissão (cor) e da iteração entre esses dois fatores.

Tabela 4. Teste $\mathrm{F}$ dos desvios relativos de vazão nos diferentes tipos de emissores

\begin{tabular}{ccrrrc}
\hline & GL & \multicolumn{1}{c}{ SQ } & \multicolumn{1}{c}{ QM } & Valor de F & Pr $(>$ F) \\
TL & 1 & 551,87 & 551,87 & 78,16 & $<2,2 \times 10^{-16 * * *}$ \\
Cor & 3 & 1745,44 & 581,81 & 82,40 & $<2,2 \times 10^{-16 * * *}$ \\
TL x Cor & 3 & 210,82 & 70,27 & 9,95 & $2,535 \times 10^{-16 * * *}$ \\
Resíduo & 367 & 2591,31 & 7,06 & & \\
\hline
\end{tabular}

*** Significativo a $0,1 \%$ de probabilidade

Depois de se verificar diferença nos tratamentos, ajustaram-se os dados de desvios relativos em função da freqüên- cia de operação da válvula solenóide para cada tipo de emissor. A Figura 4 ilustra esses resultados.

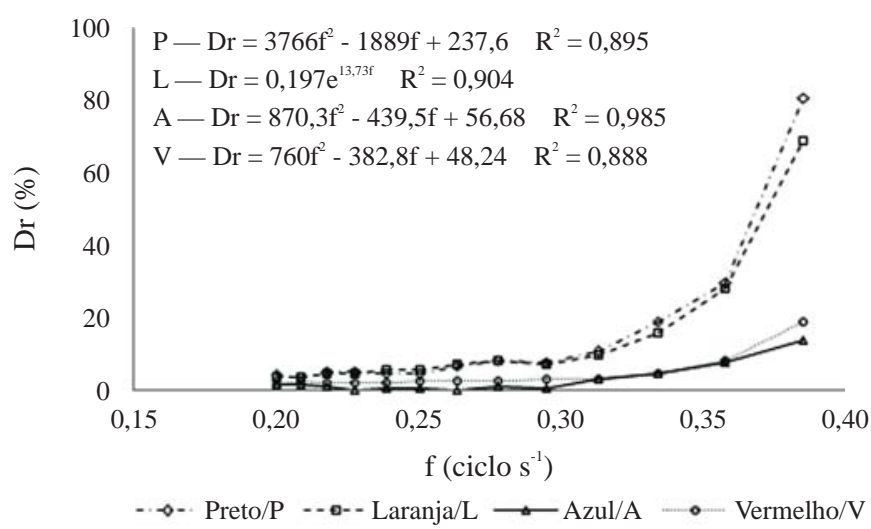

Figura 4. Desvios Relativos das vazões para diversas freqüências de operação da válvula solenóide, para todos os conjuntos de emissão

Observa-se, na Figura 5, o comportamento da uniformidade estatística (Us) das vazões observadas referentes a todos os tempos de acionamento da válvula solenóide (tl). Os emissores preto e laranja apresentaram baixos índices para intervalos de acionamento da válvula menores que $0,7 \mathrm{~s}$.

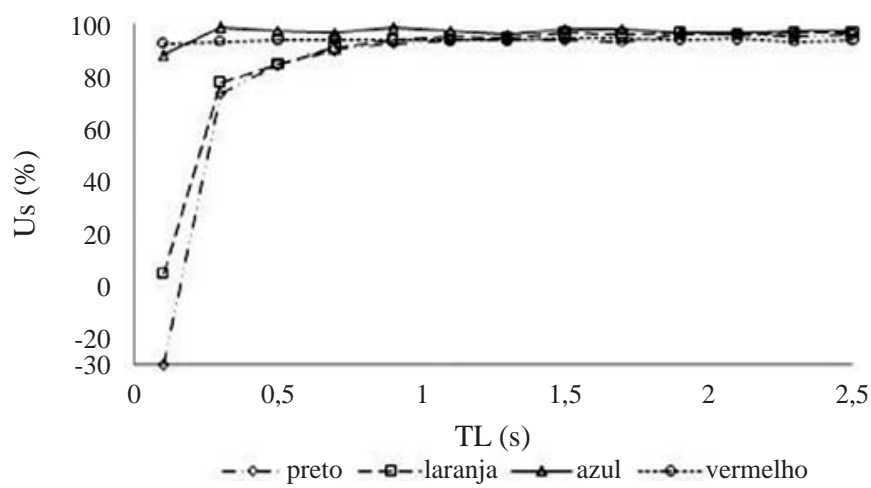

Figura 5. Uniformidade estatística das vazões observadas para os diversos tempos de ligamento da válvula solenóide, para os conjuntos de emissão preto, vermelho, laranja e azul

Para testar a precisão dos modelos ajustados, utilizou-se o índice de correlação de Pearson; esse índice é um bom indicador de precisão uma vez que, em sua expressão, estão relacionados os dados estimados e observados. Para testar a exatidão dos modelos utilizou-se o coeficiente de correlação de Willmott et al. (1985). Na Tabela 5 são apresentados os indicadores de desempenho estatístico: a) precisão - coeficiente de correlação de Pearson (r); b) exatidão - índice de concordância de Willmott (d); c) índice de confiança ou de desempenho de Camargo (c), Camargo \& Sentelhas (1997), resultado entre o produto do coeficiente de Pearson (r) e o coeficiente de Willmott (d).

De acordo com os valores apresentados na Tabela 5, temse que os modelos dos desvios relativos em função das freqüências de operação da válvula solenóide apresentaram ótimos índices de precisão e exatidão observados pelo índice 
Tabela 5. Indicadores de desempenho estatístico para testar a precisão e exatidão dos modelos propostos

\begin{tabular}{cccc}
\hline Emissor & $\begin{array}{c}\text { Coeficiente de } \\
\text { correlação de } \\
\text { Pearson (r) }\end{array}$ & $\begin{array}{c}\text { Índice de } \\
\text { concordância de } \\
\text { Willmott (d) }\end{array}$ & $\begin{array}{c}\text { Índice de } \\
\text { confiança de } \\
\text { Camargo (c) }\end{array}$ \\
Preto & 0,9898 & 0,9948 & 0,9847 \\
Vermelho & 0,9641 & 0,9849 & 0,9495 \\
Laranja & 0,9935 & 0,9967 & 0,9902 \\
Azul & 0,9693 & 0,9405 & 0,9116 \\
\hline
\end{tabular}

de confiança de Camargo, que mostrou valor maior que 0,85 . Com o intuito de minimizar o desvio relativo das taxas de aplicação da calda, tomou-se a primeira derivada das funções dos modelos propostos, igualando-as ao valor zero obtendo-se, desse modo os valores de mínimo; logo depois se determinaram as freqüências de operação (f) que minimizam o desvio relativo existente em cada emissor e os tempos aceitáveis em que a válvula solenóide deve permanecer ligada, obtendo-se seus respectivos desvios relativos. Esses dados são apresentados na Tabela 6.

Tabela 6. Freqüência ideal de operação, tempos limite de ligamento e seus respectivos desvios relativos aceitáveis para os diferentes tipos de emissores

\begin{tabular}{lrrrr}
\hline \multirow{2}{*}{\multicolumn{1}{c}{ Parâmetros }} & \multicolumn{4}{c}{ Emissor } \\
\cline { 2 - 5 } & Preto & Vermelho & Laranja & \multicolumn{1}{c}{ Azul } \\
$\mathrm{f}\left(\right.$ (ciclo min $\left.^{-1}\right)$ & 17,00 & 17,16 & 16,92 & 15,28 \\
Tempo mínimo de ligamento $(\mathrm{s})$ & 1,03 & 1,00 & 1,05 & 1,43 \\
Desvios relativos aceitáveis (\%) & 5,24 & 2,27 & 5,80 & 0,38 \\
\hline
\end{tabular}

Comparação entre os valores de vazão estimados e observados com a válvula solenóide operando com tempo de desligamento variável

De posse dos resultados obtidos no segundo experimento, determinaram-se os pontos apresentados na Tabela 7 para diferentes freqüências de operação.

Tabela 7. Desvios relativos para os quatro conjuntos de emissão variando-se o tempo em que a válvula solenóide permaneceu ligada e desligada

\begin{tabular}{|c|c|c|c|c|c|}
\hline \multicolumn{2}{|c|}{ Tempo (s) } & \multicolumn{4}{|c|}{$\operatorname{Dr}(\%)$} \\
\hline Ligada & Desligada & Preto & Laranja & Azul & Vermelho \\
\hline 0,9 & 3 & 8,21 & 9,81 & 0,24 & 1,25 \\
\hline 0,9 & 4,5 & 8,71 & 9,80 & 2,51 & 2,22 \\
\hline 0,9 & 6 & 9,18 & 10,14 & 1,17 & 2,51 \\
\hline 1,3 & 3 & 6,58 & 7,08 & 1,19 & 1,36 \\
\hline 1,3 & 4,5 & 6,64 & 7,16 & 1,29 & 1,47 \\
\hline 1,3 & 6 & 6,87 & 7,40 & 1,82 & 1,18 \\
\hline 1,7 & 3 & 5,42 & 5,82 & 0,37 & 0,87 \\
\hline 1,7 & 4,5 & 5,39 & 5,16 & 1,47 & 1,11 \\
\hline 1,7 & 6 & 5,18 & 5,81 & 2,23 & 1,42 \\
\hline 2,1 & 3 & 4,44 & 4,72 & 0,28 & 0,83 \\
\hline 2,1 & 4,5 & 4,33 & 4,42 & 0,06 & 0,47 \\
\hline 2,1 & 6 & 4,40 & 4,62 & 1,11 & 1,78 \\
\hline 2,5 & 3 & 3,79 & 4,09 & 0,20 & 0,62 \\
\hline 2,5 & 4,5 & 4,85 & 4,56 & 0,03 & 1,05 \\
\hline 2,5 & 6 & 4,95 & 4,91 & 0,80 & 0,97 \\
\hline
\end{tabular}

Observa-se na Tabela 8 que não ocorreu diferença significativa entre os desvios relativos variando-se o tempo de desligamento da válvula solenóide. Assim, nota-se a possibilidade de se utilizar qualquer tempo de desligamento para a válvula solenóide acima de 3 s.

Tabela 8. Teste $F$ dos desvios relativos de vazão nos diferentes tipos de emissores variando-se o tempo de desligamento

\begin{tabular}{ccrrcc}
\hline & GL & \multicolumn{1}{c}{ SQ } & \multicolumn{1}{c}{ QM } & Valor de F & Pr (> F) \\
TL*** & 1 & 551,87 & 551,87 & 77,4718 & $<2,2 \times 10^{-16}$ \\
Cor*** & 3 & 1745,44 & 581,81 & 81,6749 & $<2,2 \times 10^{-16}$ \\
TD & 1 & 19,21 & 19,21 & 2,6967 & 0,1014 \\
TLxCor*** & 3 & 210,82 & 70,27 & 9,8649 & $<2,8 \times 10^{-16}$ \\
TLxTD & 1 & 1,63 & 1,63 & 0,2288 & 0,6327 \\
CorxTD & 3 & 12,27 & 4,09 & 0,5743 & 0,6322 \\
TLxTDxCor & 3 & 0,86 & 0,29 & 0,0401 & 0,9893 \\
Resíduo & 359 & 2557,34 & 7,12 & & \\
\hline *** Significativo a $0,1 \%$ de probabilidade & & & \\
\hline
\end{tabular}

Para confirmar se, realmente, os intervalos propostos de tempo de desligamento (td) afetaram com significância os desvios relativos (Dr) compararam-se as vazões observadas com as vazões estimadas pela Eq. 1 nos novos intervalos. Para essa comparação se utilizou, novamente, o índice de confiança de Camargo (c). Apresentam-se, na Tabela 9, os índices obtidos na análise, constatando-se que todos os intervalos analisados indicaram pequenos erros aleatórios e erros sistemáticos, já que o valor de Camargo é maior que 0,85 para todos os intervalos.

Tabela 9. Índices de Pearson (r), Willmott (d) e Camargo (c) para a comparação entre as vazões estimadas e observadas para os intervalos de tempo analisados

\begin{tabular}{cccccc}
\hline \multicolumn{2}{c}{ Tempo $(\mathbf{s})$} & & \multicolumn{3}{c}{ Índices } \\
\cline { 1 - 2 } \cline { 5 - 6 } Ligada & Desligada & & $\mathbf{r}$ & $\mathbf{d}$ & $\mathbf{c}$ \\
0,9 & 3 & & 0,9157 & 0,9515 & 0,8714 \\
0,9 & 4,5 & & 0,9180 & 0,9518 & 0,8737 \\
0,9 & 6 & & 0,9146 & 0,9490 & 0,8680 \\
1,3 & 3 & & 0,9249 & 0,9582 & 0,8863 \\
1,3 & 4,5 & & 0,9261 & 0,9587 & 0,8879 \\
1,3 & 6 & & 0,9263 & 0,9586 & 0,8880 \\
1,7 & 3 & & 0,9278 & 0,9607 & 0,8914 \\
1,7 & 4,5 & & 0,9266 & 0,9600 & 0,8896 \\
1,7 & 6 & & 0,9293 & 0,9618 & 0,8939 \\
2,1 & 3 & & 0,9302 & 0,9625 & 0,8954 \\
2,1 & 4,5 & & 0,9312 & 0,9630 & 0,8967 \\
2,1 & 6 & & 0,9320 & 0,9635 & 0,8979 \\
2,5 & 3 & & 0,9321 & 0,9638 & 0,8983 \\
2,5 & 4,5 & & 0,9316 & 0,9628 & 0,8969 \\
2,5 & 6 & & 0,9296 & 0,9619 & 0,8942 \\
\hline
\end{tabular}

Com o exposto se comprova a utilização de qualquer tempo de desligamento para a válvula solenóide maior que $3 \mathrm{~s}$; entretanto, deve-se escolher um tempo que garanta um molhamento uniforme da estrutura foliar da cultura, salientando-se que, atualmente, existem pivôs centrais que podem 
atingir uma velocidade de deslocamento de $344 \mathrm{~m} \mathrm{~h}^{-1}$ utilizando-se pneus de 0,124 m de largura e 0,38 m de diâmetro. De acordo com Vilela et al. (2004) os bocais pretos e azuis apresentam alcances superiores a $0,5 \mathrm{~m}$ enquanto os alcances dos demais modelos se encontram compreendidos entre 0,4 e 0,5 m. Considerando-se que na extremidade do último vão do pivô central se utilizarão emissores de cor preta e se admitindo uma sobreposição de $0,15 \mathrm{~m}$ no sentido de caminhamento do pivô central, recomenda-se a utilização da válvula solenóide com tempo de desligamento menor que $9 \mathrm{~s}$.

Os desvios entre as vazões estimadas e observadas ocorrem devido a diversos fatores como: 1) o tempo de resposta do acionamento da válvula solenóide para marchas que implicam pequenos tempos de acionamento; 2) o aumento de pressão na barra de pulverização em virtude do golpe de aríete da válvula solenóide; 3 ) a celeridade descrita no percurso da água dentro da barra em altas freqüências de operação da válvula solenóide, dentre outros.

\section{CONCLUSÕES}

1. Os modelos propostos para determinação de desvios relativos em função da freqüência de operação da válvula solenóide, para os diferentes tipos de emissores, apresentaram excelentes índices de precisão e exatidão.

2. Os emissores de diâmetro 1,212 (preto), 1,016 (vermelho) e $1,020 \mathrm{~mm}$ (laranja) mostraram desvios relativos inaceitáveis para um tempo de ligamento da válvula solenóide menor que $1 \mathrm{~s}$.

3. O emissor de diâmetro 0,621 mm (azul) indicou desvio relativo inaceitável para um tempo menor que $1,4 \mathrm{~s}$.

4. Os emissores de diâmetro 1,212 (preto) e 1,020 mm (laranja) apresentaram índices inaceitáveis de uniformidade estatística para um tempo de ligamento da válvula solenóide menor que $0,7 \mathrm{~s}$.

5. Os emissores de diâmetro 0,621 (azul) e 1,016 mm (vermelho) apresentaram bons índices para tempos de ligamento menores que $0,7 \mathrm{~s}$ e excelentes índices de uniformidade estatística para os demais tempos de ligamento da válvula solenóide.
6. Os desvios relativos dos emissores para tempos de desligamento da válvula solenóide compreendidos entre 3 e 9 s são aceitáveis necessitando-se de atenção para a escolha de um tempo que permita um molhamento uniforme da estrutura foliar.

7. Enfim, todos os emissores apresentaram excelentes índices de uniformidade estatística para um tempo de desligamento da válvula solenóide maior que $3 \mathrm{~s}$.

\section{LITERATURA CITADA}

Alves, D. R. B. Distribuição de nitrogênio e potássio na cultura de milho aplicados via pivô central. Piracicaba: ESALQ/USP, 2000. 99p. Tese Doutorado

Baio, F. H. B. Aplicação localizada de defensivos baseada variabilidade espacial das plantas daninhas. Piracicaba: ESALQ/ USP, 2001. 113p. Dissertação Mestrado

Bralts, V. F.; Wu, I. P; Gitlin, H. M. Emitter plugging and drip irrigation lateral line hydraulics. Transactions of the ASAE, v.25, p.1274-1281, 1982.

Camargo, A. P.; Sentelhas, P. C. Avaliação do desempenho de diferentes métodos de estimativa da evapotranspiração potencial no estado de São Paulo, Brasil. Revista Brasileira de Agrometeorologia,v.5, p.89-97, 1997.

Cupery, E. W.; Application accuracy. In: Whorter, C. G. M.; Gebhardt, M. R. Methods of applying herbicides. West Clark: WSSA, p.63-84, 1987.

Farahani, H. J.; Shaner, D. L.; Buchleiter, G. W.; Bartlett, G. A. Evaluation of a low volume agro-chemical application system for center pivot irrigation. Applied Engineering in Agriculture, v.22, p.517-528, 2006.

Vilela, A. P.; Dourado Neto, D.; Botrel, T. A. Desenvolvimento de um sistema de pulverização acoplado à pivô central. Revista Brasileira de Engenharia Agrícola e Ambiental, v.8, p.311-315, 2004.

Vilela, L. A. Metodologia para dimensionamento de um sistema de pulverização acoplado a pivô central, Piracicaba: ESALQ/ USP, 2002. 128p. Tese Doutorado

Willmott, C. J.; Ckleson, S. G.; Davis, R. E. Estatistics for evaluation and comparison of models. Journal of Geophysical Resarch, v.90, n.C5, p.8995-9005, 1985. 